\title{
The Secondary-Student Science Learning Motivation in Korea and Indonesia
}

\author{
Arif Rachmatullah ${ }^{1}$, Fenny Roshayanti ${ }^{2}$, Sein Shin ${ }^{3}$, Jun-Ki Lee ${ }^{3}$, Minsu Ha ${ }^{1 *}$ \\ ${ }^{1}$ Kangwon National University, Chuncheon, SOUTH KOREA \\ ${ }^{2}$ Universitas PGRI Semarang, Semarang, INDONESIA \\ ${ }^{3}$ Chonbuk National University, Jeonju, SOUTH KOREA
}

Received 16 September 2017 - Revised 13 March 2018 • Accepted 13 April 2018

\begin{abstract}
The previous studies on motivation have merely revealed the effects of gender, educational level, and country; however, the effect of the interactions between these variables on motivation has not yet been uncovered. The present study aims to statistically examine whether or not the interactions between these three variables can significantly impact the student science learning motivation. A set of the Science Motivation Questionnaire-II (SMQ-II) was administered to 867 Korean and 954 Indonesian secondary students (middle and high schools), and the Rasch analysis was performed to identify the validity and reliability of the instrument. To reveal the aim of this study, a three-way ANOVA and Pearson-correlation tests were used. Based on the findings, the interactions between country, gender, and educational level exerted significant effects on the student science learning motivation, as well as the remaining motivational components. The findings are discussed with respect to the factorial complexity that contributes to the student science learning motivation and the differences between the learning-motivation levels of the students of the two countries.
\end{abstract}

Keywords: cross-cultural, Indonesia, Korea, science motivation, secondary student

\section{INTRODUCTION}

The study of the student's cognitive structure has been one of the longstanding topics in the body of science education research. Indeed, the student's cognitive construct is directly associated with the scientific contents that are provided for the student's school learning, and most people think that the outcome of science learning is the development of a cleverness and an understanding of all of the science contents. Therefore, the investigative studies regarding the student cognitive construct have been exaggerated, while a collection of accurate findings has been accumulated. But, due to the investigational focus on the student's cognitive construct, other constructs besides the cognitive construct continue to be marginalized and are explored to a lesser extent (e.g. the affective constructs including the motivation and the interest regarding science learning) (Koballa \& Glynn, 2007).

In general, motivation refers to the goal-directed activity process that exists in every individual mind (Schunk, Pintrich, \& Meece, 2008). Specifically, the motivation to learn science that has been stated by Lee and Brophy (1996) is the student's desire to achieve a goal for an improved understanding of science including his or her involvement in science-related tasks and activities. Science education researchers (e.g., Koballa \& Glynn, 2007; Vedder-Weiss \& Fortus, 2013) have argued that an investigation of the student science learning motivation needs to recognize the motivation as a crucial stimulus of the student's cognitive structure. In addition, the student science learning motivation is also known as an important aspect of the prediction of a student's later science career and education (Maltese \& Tai, 2010).

(c) 2018 by the authors; licensee Modestum Ltd., UK. This article is an open access article distributed under the terms and conditions of the Creative Commons Attribution License (http://creativecommons.org/licenses/by/4.0/).

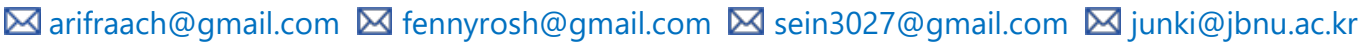




\section{Contribution of this paper to the literature}

- An extensive review of the science education system of Indonesia and Korea is provided.

- A statistical demonstration of the interaction effects between country, gender, and educational level in terms of the student's science learning motivation.

- Support regarding the idea that the student learning motivation is a complex psychological aspect that is not dependent on only one factor.

The reason that the motivation impacts on the student learning outcome is the fundamental nature of the motivational aspect of the student learning approach that is defined as the way that a student processes academic tasks (Chin \& Brown, 2000); that is, the entire student's learning process is driven by the student motivation. Yet, the actual motivational magnitude of the student in the learning of science varies, and Osborne, Simon, and Collins (2003) and Tang and Neber (2008) argue that the student motivation is impacted by several socially related factors, with country, gender, educational level, and age being of particular importance. Alexander, Johnson, and Kelly (2012), for instance, found that in the early childhood and primary-school years of American girls, the subjects seemed to show a lesser interest and motivation regarding the learning of science-related topics compared with their male peers. Similar to Alexander et al. (2012), in a sample of British primary-school students, Jarvis and Pell (2005) found a lower pre-intervention motivation among the girls regarding the learning of science compared with the boys. In a sample of Turkish primary-level students, however, Cavas (2011) did not find any gender differences in the learning of science. Moreover, at the higher levels of education and the student age, the 2015 findings of one of the notable triennial international assessments, the Program for International Student Assessment (PISA), regarding 15-year-old students showed that the gender differences regarding the motivation to learn science varied between countries (Organization for Economic Cooperation and Development [OECD], 2016).

Moreover, regarding the educational year and the student age, the study of Vedder-Weiss and Fortus (2011) found a declining trend of the science learning motivation for Israeli students from the fifth grade to the eighth grade. Similar declining trends were also obtained by Galton (2009), who studied British sixth and seventh graders. However, a study on Filipino students conducted by Libao et al. (2016), where the educational year was also considered, found that the higher levels of academic performance positively correlate with the student science learning motivation. The evidences from these studies indicate the uniqueness of different countries, each with a different culture and socioeconomic status, with respect to the gender and age influences on the science learning motivation.

Regarding the complexity of the science learning motivation, which is not dependent on only one social factor, the student science learning motivation may be affected by the interactions between gender, educational year, and country. To date, researchers have not examined these three dependent variables together in terms of the student science learning motivation; thus, the current study attempts to confirm the complexity of the science learning motivation through a consideration and examination of the influence of those three significant factors on the science learning motivation based on statistical findings. Prior to the presentation of the findings and discussion of this study, a literature review regarding the science learning motivation and descriptions of the scientific- and generaleducation types of Indonesia and Korea are provided.

\section{LITERATURE REVIEW}

\section{The Science Learning Motivation and the Roles of Educational Level and Gender in its Shaping}

According to the social cognitive theory (SCT) proposed by Bandura (1986), human behavior is influenced by the reciprocal interactions between individual factors such as perception, belief, emotion, culture, and society. In addition to the SCT, it is assumed that individuals are active beings who can individually adjust their behaviors and perceptions to achieve their desired goals. In view of the SCT, motivation is elucidated as a goal-directed process that involves energized, directed, and sustained activities (Schunk \& Usher, 2012), and it is influenced by a fair number of factors such as various cognitive, emotional, and surrounding-environment factors. In terms of the high motivation that can be achieved by students, Murayama et al. (2013) and Lee et al. (2016) stated that it is closely related to a student's participation in the so-called "active learning activities" as part of his or her effort to gain a desirable academic achievement; therefore, many educators have attempted to understand the learning-motivation characteristics. In particular, the focus of many of the prior studies that are related to the learning motivation comprises factors such as the individual perception of self (e.g., self-efficacy), the task value, and the student intended goal (Pintrich, 2003; Wigfield, Cambria, \& Eccles, 2012). 
In the field of science education research, only a few investigative studies regarding a comparison of the student affective domains with the student cognitive factors such as concept, theory, and inquiry have been completed (Fortus, 2014). Among the studies on the affective domains, the attitude toward science was included in the most scrutinized study, while the research on the student science learning motivation is very limited (Fortus, 2014). However, the science learning motivation has been emphasized as a core study element due to its essence that is in accordance with the student participation in science learning activities, as well as the student intention regarding the attainment of a higher academic achievement (Fortus, 2014; Lee et al., 2016; Palmer, 2005). Additionally, experts have found that several social factors play roles in the shaping of the student learning motivation, including that regarding science learning (e.g., Osborne et al., 2003; Tang \& Neber, 2008), and they found that the student learning motivation is shaped by country (including culture and economic status), gender, and educational level. The focus of this section is the elucidation of the influences of the educational level and the gender in terms of the student learning motivation, while that regarding the country effect is described later in the literature-review section of the present paper.

Several educational motivation experts have explained the influence of the student educational level, as well as the student age, the school curriculum, and the difficulty of the learning contents, in the shaping of the student motivation regarding the learning of particular school subjects (e.g., Gottfried, Fleming, \& Gottfried, 2001; Lepper, Corpus, \& Inyenger, 2005; Meece, Anderman, \& Anderman, 2006; Pintrich, 2003; Urdan \& Schoenfelder, 2006). Based on the longitudinal studies on motivation that were conducted by Gottfried et al. (2001) and Lepper et al. (2005), the student learning motivation decreased with the increasing of the student age, showing that the learning motivation of students with higher educational levels (mostly older) is lower. Gottfried et al. (2001) further explained that the decreased learning-motivation trend, especially in science, is caused by the higher anxiety levels of the students at the higher educational levels. The competitiveness regarding grades, activities, and the collegeadmission process at the higher educational levels increases the students' anxiety levels, thereby reducing their learning-effort levels. Moreover, Pintrich (2003) and Urdan and Schoenfelder (2006) have claimed that the school and classroom environments and facilities contribute to the student learning motivation; that is, it is known that schools and classrooms that comprise more facilities and provide more effective teaching methods positively influence the student learning process.

Regarding the manner in which gender shapes the student learning motivation, especially in science, it has been frequently argued that the sporadic stereotyping of science subjects as more masculine is the cause of the gender gap in terms of the science learning motivation (e.g., DeBacker \& Nelson, 2000; Meece, Glienke, \& Burg, 2006). A study that was conducted by DeBacker and Nelson (2000) found that both male and female students expressed the stereotypical notion regarding the masculine nature of science subjects. Meece et al. (2006) reviewed the sources of the gender stereotyping in terms of the learning motivation and found the following three sources that correlate with each other: parental influence, schooling, and the sociocultural factor. Regarding the parental influence, the stereotypical cultural gender perspectives that favor males more in terms of the excelling of students in the science field compared with females have heavily influenced the way that parents treat their children on the basis of gender. When parents implement this kind of stereotyping, their children's study-field focus tends to be based on their surrounding beliefs; in turn, the parents tend to support this focus by providing the corresponding materials and through the controlling of their schedules accordingly (Larson, Dworkin, \& Gillman, 2001; McHale et al., 2004). Consequently, both genders show higher motivation levels in the fields that are derived from their parents' suggestions.

With respect to the schooling influence, Jussim and Harber (2005) argue that the learning motivation is likely to be influenced by the teacher attitudes and perceptions toward the learning activities and interactions in the classroom. In classrooms, the teachers tend to prefer students who are actively engaged in the classroom interactions, and based on the study that was conducted by Jones and Dindia (2004) boys are more active and reflective during the learning process. Consequently, teachers are inclined to interact more with boys than with girls, leading to a decrease of the girls' learning motivation. Moreover, in regard to the mostly abstract concepts of the science subjects, the stereotypical notion indicates that they are more easily learned by the male students compared with the female students, and this also influences teachers in terms of their more favorable treatment of male students.

Regarding the sociocultural factor, the learning-motivation gender gap varies between different cultures and socioeconomic levels (Graham \& Taylor, 2002; Meece \& Kurtz-Costes, 2001). But, similar patterns have been found in most cultures, where the males are bestowed a higher position, as well as greater educational opportunities, than the females. Consequently, in most cultures, the learning motivation of the males tends to be higher than that of the females.

A number of experts including Glynn et al. (2011) have expanded the meaning of the SCT-derived definition of motivation in the context of science learning. Glynn et al. (2011) have defined the science learning motivation in the following way: "[the] internal state arouses, directs, and sustains science-learning behavior" that consists of the 
self-efficacy, self-determination, intrinsic motivation, career motivation, and grade motivation in science. They empirically confirmed that these five motivational components interact with each other and constitute the student science learning motivation. The five factors are subsequently described.

Self-efficacy. In SCT, it is assumed that self-efficacy is a key factor in the self-regulation mechanism of human behavior (Bandura, 1986). Self-efficacy refers to one's belief in his or her ability to perform a specific behavior or to reach a specific goal; therefore, self-efficacy in science implies a belief in the student's ability to engage in science subjects or specific science-related behaviors (Mason et al., 2012). An individual with a high self-efficacy should be well synchronized for the performance of certain behaviors and the achievement of desirable goals (Bandura, 1997). A high self-efficacy is also known as a key factor in the prediction of high achievements (Britner, 2008; Lau \& Roeser, 2002; Lee et al., 2016). Conversely, since the influence of a successful mastery experience on the formation of selfefficacy is definitive, the formation and effect of self-efficacy could make it a representative example of the active interactions between the behavior and the personal attributes that are defined in the SCT. A number of studies have suggested that self-efficacy is related to positive aspirations regarding science and science-career decisions (Dalgety \& Coll, 2006; Nugent et al., 2015).

Self-determination. Self-determination is a factor that contributes to one's motivation and is associated with one's self-regulation. Self-determination refers to the autonomy and the control that are perceived regarding a particular activity or behavior. Regarding self-determination theory (SDT), Ryan and Deci (2000) argue that self-determination is an essential component of a student's intrinsic motivation, which apparently correlates with the extrinsic motivation as well. For instance, according to one of the SDT sub-theory called organismic integration theory (OIT), it is assumed that an individual tends to be initially disinterested in being a participant in an activity, but the external environment encourages the individual to perform such uninteresting activities. The external encouraging factor or the factor that is from the internalization of the external regulation, in addition to the key of this internalization, is called autonomy (Ryan \& Deci, 2000). That is, once a student has perceived his or her own behavior as self-determined, the learning behavior that is gained by the student from the external regulation is gradually internalized, and eventually the student is intrinsically motivated.

Intrinsic motivation. Intrinsic motivation refers to a state in which the intent of an act consists of enjoyment and interest. Enjoyment and interest are known as the representative elements of the intrinsic motivation. In addition, a student who is intrinsically connected with science is more likely to participate in science-related activities, recognize positive images of his or her own self, and aspire to work in a science field (Nugent et al., 2015). This motivation is in contrast to the extrinsic motivation, which refers to the student learning that is for the receipt of rewards or the avoidance of punishments (Ryan \& Deci, 2000).

Grade motivation. One of the most influential motivational components for a student in terms of learning is the attainment of a high score. It is known that students with a high grade motivation pursue a higher grade and/or score in their science learning; therefore, the role of the grade is important for students in science learning activities. In particular, the score is a positive motivational component, as it can be useful information in the processes of the identification of individual-achievement levels and the controlling of learning activities (Elliot \& Moller, 2003). In terms of this grade-based motivation, however, negative effects such as the decreasing of the student autonomouslearning motivation and the increasing of only the performance-avoidance goal can be influential (Pulfre, Buchs, \& Butera, 2011).

Career motivation. Career motivation refers to the science learning motivation, because it can help students as they pursue their desired future jobs. A student will possess a high career motivation when the student thinks that his or her science learning can provide a major contribution in the pursuance of the student's desired career. In this sense, science learning is considered as an extrinsic motivation or an instrumental motivation, because it is seen as a means of job attainment (Glynn et al., 2011; OECD, 2016; Wigfield et al., 2012). Glynn et al. (2009) found that the science learning motivation of non-science major students is related to their perception of the relevance of the science learning to their career. Accordingly, the career motivation is not only evident for those students who want to gain a science career, but it is also relevant for many students who are seeking a science-related career. The findings of the study that was conducted by Shin, Ha, and Lee (2017) suggest that the effect of the career motivation on the science learning motivation and the career choices of most students is positive.

\section{Differences between the General and Science Education of Korea and Indonesia}

\section{Korean and Indonesian education in context}

Korea is known as part of the Confucian culture along with the other East Asian countries, Japan, Taiwan, and China. Korea has been influenced by the Confucian culture for over 1,500 years, and many aspects and customs of Confucian culture still exist in the present time. In Confucian culture, education is greatly emphasized not only in terms of personal growth, but also in terms of societal stability. For a couple of centuries, the interactions between 
the Confucian and collectivist cultures have influenced the Korean education system. Due to the collectivist culture, children's education has been seen as a family matter rather than a child matter; consequently, families express much interest and expectation regarding the education of their children and invest greatly in this education. The combination of the influences of Confucian culture and a family centeredness has resulted in a Korean passion for excessive education (Seth, 2002). One of the indicators of this educational passion is Korea's high tertiary-education completion rate. According to recent reports on the OECD countries, the tertiary-education completion rate among the young people of Korea is the highest among the OECD countries (OECD, 2016). The Korean enthusiasm for higher education and the achievement of high educational levels by Korean students have been evaluated as a driving force of the economic development that has rapidly occurred over the 60 years since the Korean War (Jones, 2013).

As we have seen, Korea has a national curriculum with a single track 6-3-3 system. The latest national curriculum is the '2015 revised curriculum' (Ministry of Education, 2015). The Korean '2015 revised curriculum' is divided into common basic education (compulsory) with grade 1-9 and select-centered education from grade 10 to 12. The 2015 revised science curriculum is designed to improve student core competencies such as scientific thinking, scientific inquiry ability, scientific problem solving ability, scientific communication, science related participation and lifelong learning ability. In common basic education, it is noted that a "science" subject is systematically organized with core concepts within 'motion and energy,' 'material,' 'life,' and 'earth and universe.' In the use of a select-centered science curriculum, all students in Grade 10 learn the subjects of 'Integrated Science' and 'Science Inquiry Experiment' to cultivate scientific literacy, and from the 11th grade onward, the students can select advanced courses based on their own career development or individual interest. Advanced courses in a select-centered curriculum include 11 subjects such as Physics 1 \& 2, Life Science 1 \& 2, Chemistry 1 \& 2, Earth Science 1 \& 2, History of Science etc.

Indonesia is not only known as one of the most bio-diverse countries in the world, and the fourth mostpopulated, but it has also been recognized as the most linguistically and culturally diverse country due to the existence of 700 living languages and 300 ethnic groups. In addition, Indonesia is known as a religious country, not as secular or Islamic, even though more than $80 \%$ of Indonesia's citizens adhere to the Islam religion (BPS, 2013), as five other religions (Protestantism, Catholicism, Hinduism, Buddhism, and Confucianism) are legally considered regarding Indonesia's citizens. It is necessary, however, for Indonesians to adhere to at least one of these six religions. Indonesia's own Pancasila ideology was designed to cope with and accommodate the various cultures and the diversity of Indonesia. Religiosity, though, is more essential than culture in every community and society of Indonesia (Parker, 2017), and not least in terms of education and the national curriculum. In the newest published Indonesian curriculum, "Curriculum 2013", tolerance and spiritual aspects are two of the four core educational competencies, especially regarding the science education. The other two core competencies are knowledge and skill. The significance here is that every taught subject including science should not only be used to enhance the student knowledge and skill in the particular subjects, but also, enhancements of the student tolerance and spiritual aspects are expected. Besides, the teachers as well as the students are encouraged to utilize the resources (natural and cultural) that exist near their school or their local area in their teaching and learning activities. This kind of effort is a way of coping with the diversity of the Indonesian people, as the students are often asked to go outside of the classroom to learn more about the concepts they are being taught.

Moreover, science curriculum in Indonesia is quite different to what it is in Korea, especially for the high school level. Indonesia and Korea have quite a similar science education system for K-9 students, which notes that the science curricula is delivered in class as an effort to develop children's scientific thinking, scientific inquiry ability and scientific problem solving ability. In Indonesian high schools, science subjects are not divided into lower upper level knowledge and students do not have the authority in selecting the classes. If in Korea students can choose which science subjects that they prefer to be advanced to by taking both basic and advanced classes; it is different however in Indonesia, as it is considered necessary for students to take all science classes - notably the subjects of biology, chemistry and physics for both the lower and upper levels of the student's learning in the classroom.

Additionally, besides the educational-system differences between Indonesia and Korea, both countries share a number of similarities. Most of all, both countries have adopted a national science curriculum with several similar educational directions. For example, in Indonesia's "Curriculum 2013," the development of the scientific behavior and attitudes as well as the scientific knowledge is more emphasized than before. Especially, scientific skills such as observation, questioning, exploration, association, and communication have been included as educational objectives in terms of the preparation of the competencies that are needed by a citizen of the 21st century.

The emphasis of Korea's newest curriculum, "The 2015 Revised Curriculum," is also inquiry-based activities that are for the enhancement of the student scientific skills such as observation, experimentation, argumentation, and communication, rather than merely an understanding of the student basic-science concepts (Ministry of Education, 2015). Especially, the new Korean curriculum is designed for the student interest and enjoyment in 
science learning that is to a greater extent compared with the previous curricula, as the Ministry of Education seeks to solve the problem of the much lower affective-factor level of Korean students compared with the international average (OECD, 2016). For this purpose, the science learning emphasis comprises situations that are relevant to everyday experiences. This direction of the Korean revised national curriculum of 2015 is similar to the Indonesian national curriculum that encourages science teaching and learning within local contexts.

Moreover, another prevalent similarity comes from the types of cultural value that are upheld by the citizens of both countries, both of which are collectivist societies (Leigh \& Van der Eng, 2009). The origin of the collectivist society in Korea is Confucian culture, while it is the acculturation of traditional and Islamic cultures in Indonesia. Regarding the collectivist culture, Hofstede (2003) explains that the people who uphold this kind of culture tend to easily maintain human relationships, and they also tend to be friendlier toward other nationalities, leading to an ease regarding the sharing of resources including motivation. Moreover, collectivism is also characterized by the traits of interpersonal sharing, cooperation, and support (Hofstede, 2003).

\section{Korean and Indonesian science education in the view of international studies}

The quality of the general education, and specifically that of the science education, can be seen from the achievements of the students in the international assessment programs. Previously, in many of the international academic-achievement evaluations such as the Trends in International Mathematics and Science Study (TIMSS) and the Programme for International Student Assessment (PISA), Korean students have always shown outstanding levels of science achievement compared with Indonesian students. Specifically, 15-year-old students from Korea have reached the highest ranking among the OECD countries since the commencement of the PISA, and this is in contrast with the Indonesian placements that have always been in the 10th-lowest ranks since the first PISA. In the findings of the most recent PISA 2015, the Korean students placed among the fifth-highest OECD member countries and are $11^{\text {th }}$ among the total of 70 countries. While the Indonesian students placed in the much lower ranking of 62nd place (OECD, 2016).

Further, in the findings of the TIMSS, Korean eighth graders showed their strong science abilities with a fourthplace achievement among the participating countries (Mullis et al., 2016). Although Indonesia did not participate in the TIMSS eighth-grader assessment, it did participate in the fourth-grader assessment. In terms of the science achievement, the quality of Korea's science education is undoubtedly high, as is suggested by the outstanding second-rank placement that was obtained by the Korean fourth-graders in the TIMSS 2015; meanwhile, the ranking of the Indonesian fourth-graders among the 47 participating countries is 44 . In addition, a 20 -year analysis of the TIMSS results shows that the Korean-student scientific achievement steadily improved over the period from 1995 to 2015 (Mullis et al., 2016).

The findings from the affective aspects that were obtained for both countries, however, are the opposite of the countries' scientific achievements. In the findings of the PISA 2015, regarding the science learning motivation, the average of the Korean students is lower than the averages of all of the participating countries, while one of the highest science learning motivation averages is from the Indonesian students (OECD, 2016). Similar findings were obtained from the TIMSS 2015 in terms of the topic "How much do the students like to learn science?"; that is, the Indonesian fourth-graders are in the seventh rank, with $77 \%$ of them indicating that they "very much like learning science." In contrast, the Korean fourth-graders are in the second-last rank (46 out of 47), with just $42 \%$ indicating that they like science learning, and this percentage is less than the international average of 56\% (Mullis et al., 2016).

\section{The role of country in the shaping of the student science learning motivation}

Chiu and Xihua (2008) argue that country including the culture and the cultural values of particular countries contribute to the development of the student learning motivation. Moreover, they also argue that the socioeconomic statuses of particular countries also influence the student learning motivation. Based on the United Nations International Children's Emergency Fund (UNICEF), higher socioeconomic levels and gross domestic product (GDP) values positively align with the science learning motivation of a country's children (UNICEF, 2001). This finding is underpinned by the ability of richer countries to provide sufficient materials, and also more advanced materials, including books and other facilities, and these can stimulate the student learning motivation, thereby leading to a higher achievement as well. As explained by Pintrich (2003) and Urdan and Schoenfelder (2006), more effective learning environments positively contribute to the increasing of the student science learning motivation. Broadly speaking as regarding the countries as the subject of current research, Indonesian and Korea, OECD (2017) reported that Korea uses $2.3 \%$ of GDP as expenditure of their education, and this value is above the OECD's average which is $2.1 \%$. However Indonesia only uses $1.2 \%$ of its GDP for educational funding purposes country-wide.

With respect to the culture and the cultural values that are held by the people of a particular country, Chiu and Xihua (2008) reviewed the cultural types that correlate with the learning motivation. They found that students who live in countries with egalitarian cultures and collectivist societies - the cultures that, according to Hofstede (2003), 
Table 1. Dimensionality-analysis results

\begin{tabular}{llccccc}
\hline Country & Number of Dimensions & Final Deviance & AIC & Chi-square & df & $\boldsymbol{p}$-value \\
\hline \multirow{2}{*}{ Indonesia } & One-dimension & 56377.98 & 56579.98 & 630.84 & 24 & 0.00 \\
\cline { 2 - 8 } & Five-dimension & $\mathbf{5 3 8 0 7 . 7 6}$ & $\mathbf{5 4 0 3 7 . 7 6}$ & $\mathbf{1 9 3 8 . 3 0}$ & $\mathbf{2 0}$ & $\mathbf{0 . 0 0}$ \\
\hline \multirow{2}{*}{ Korea } & One-dimension & 46259.16 & 46461.16 & 360.99 & 24 & 0.00 \\
\cline { 2 - 8 } & Five-dimension & $\mathbf{4 2 1 5 7 . 3 0}$ & $\mathbf{4 2 3 8 7 . 3 0}$ & $\mathbf{6 4 1 . 0 2}$ & $\mathbf{2 0}$ & $\mathbf{0 . 0 0}$ \\
\hline \multirow{2}{*}{ Both Countries } & One-dimension & 102790.50 & 102982.50 & 1279.84 & 24 & 0.00 \\
\cline { 2 - 9 } & Five-dimension & $\mathbf{1 0 0 5 1 8 . 8 9}$ & $\mathbf{1 0 0 7 3 8 . 8 9}$ & $\mathbf{1 3 8 5 2 . 2 4}$ & $\mathbf{2 0}$ & $\mathbf{0 . 0 0}$ \\
\hline
\end{tabular}

uphold the perception of similarity in terms of human relationships and maintain the value of sharing - tend to possess higher motivational levels and obtain higher achievements in educational contexts. Whereas, in countries that uphold an individualistic culture, the student motivation tends to be lower, leading to lower achievements. Chiu and Xihua (2008) further explain that this finding may be caused by the sharing culture, where the parents and teachers in a collectivist society attempt to support and provide for the student educational needs more than those in an individualistic culture.

\section{RESEARCH QUESTIONS}

In this paper, it is crucial to recognize that the science learning motivation does not depend solely on one variable such as country, gender, or even educational level, which is how it has been unveiled in most of the previous studies. The contributing factor of the student science learning motivation is more complex. Therefore, the following research questions were examined in the study of the science learning motivation of Indonesian and Korean secondary students:

1. Do the interactions between country, gender, and educational level exert an effect on the secondary students' science learning motivation?

2. What is the extent of the effect of the interactions between country, gender, and educational level on the associations between one motivational component and the other motivational components?

\section{METHOD}

\section{Participants}

The data regarding the middle-school and high-school students' science learning motivation were purposively collected from the two countries, Korea and Indonesia, which have different cultural and educational systems with respect to teaching and the learning of science. For this study, students who were in the second grade $\left(8^{\text {th }}\right)$ of middle school and the first grade $\left(10^{\text {th }}\right)$ of high school were selected as representative segments of middle- and high-school students. The totals of 867 Korean and 954 Indonesian students participated in the survey that was conducted during the years of 2015 and 2016.

Demographic data, particularly gender and educational level, were also collected from the participants. The Korean data comprises $36 \%$ of middle-school student data and $64 \%$ of high-school student data. The Korean middle-school student data comprises $55 \%$ of male-student data and $45 \%$ of female-student data, and the Korean high-school data comprises $63 \%$ of male-student data and $37 \%$ of female-student data. In terms of the Indonesian data, given the two kinds of school in the country, which are the general public school (middle school/SMP and high school/SMA) and the Islam-based school (Madrasah Aliyah/MA for high school), the data also consists of student responses from both types of school. The Indonesian data comprises $38 \%$ of middle-school student data and $62 \%$ of high-school student data. The Indonesian middle-school student data consists of $42 \%$ of male-student data and $58 \%$ of female-student data, while the high-school student data consists of $44 \%$ of male-student data and $56 \%$ of female-student data.

\section{Instrument}

Twenty-five items of the Science Motivation Questionnaire II (SMQ-II), with five levels of the Likert scale ( $1=$ strongly disagree to $5=$ strongly agree), were developed by Glynn et al. (2011) and these were utilized as the research instrument in the investigation of the student science learning motivation. The SMQ-II was selected as the research instrument because its validity has been tested by developers for both science-major and non-sciencemajor samples; furthermore, it was also validated using the IRT-Rasch method and the classical test theory (CTT), leading the authors of the present study to believe that reliable and valid data could be obtained with the use of the SMQ-II research instrument. The SMQ-II was validated using the authors' current data, which is both the Indonesian and the Korean data, and these are provided below. 


\section{Dimensionality and item fits}

The SMQ-II consists of five different constructs of the science learning motivation that assess the intrinsic motivation, career motivation, grade motivation, self-determination, and self-efficacy of a student. These five SMQII constructs have been statistically validated through an exploratory factor analysis that is based on the CTT method. As a complementary method, an investigation of whether the SMQ-II can be treated as one motivational construct or five constructs was also undertaken using the item response theory (IRT)-Rasch method for which a multidimensional analysis was performed. The nature of the running of the multidimensional analysis ensured that the numbers of dimensions that are present in the Korean and Indonesian data were psychometrically uncovered. As the final deviance, the Akaike Information Criterion (AIC) and the chi-square test were employed to define the goodness-of-fit model that was obtained from the multidimensional analysis including the comparison of a one-dimensional model and a five-dimensional model. The benchmarks of the lower final deviance and the AIC and the higher chi-squared distribution compared with the other comparator models were used as the indicators of the best model (Adams \& Wu, 2010).

As shown in Table 1, the Korean and Indonesian data, and even the whole united data, were better fitted using the five-dimensional Rasch model rather than the one-dimensional model. It is suggested that the treatment of the Korean and Indonesian secondary-student SMQ-II data as five constructs would gain more valuable and meaningful results than a treatment of the data as only a single construct. The treatment of the SMQ-II as a fivedimensional instrument with the validity of every item and the reliability of every construct was also suggested. The item validity was assessed based on the mean-square (MNSQ) for which the cut-off is in the region from 0.7 to 1.4 (Wright \& Linacre, 1994). Most of the item MNSQ values met the cut-off. Two items were diagnosed as misfitting items when the one-dimensional model was used for the SMQ-II data, and only one item, which is lower than 0.7 (career-motivation item-number 3), was diagnosed as a misfitting item - it can be called the "overfit item" - when the five-dimensional model was applied to the Indonesian and Korean data. According to Linacre (2012), it is not crucial that the MNSQ values that are lower than the benchmark are compared with those that are higher than the benchmark. These findings suggest that the five-dimensional treatment of the SMQ-II is more effective than the one-dimensional treatment.

\section{Reliabilities}

In terms of the reliabilities, the person and item reliabilities were obtained from the IRT-Rasch analysis. Regarding the person reliability, which is defined as the probability of the participant's consistency regarding the correct answer on every item as scaled by its difficulties (Linacre, 2012), the coefficients that were obtained from the analysis are all higher than 0.8 when the Korean and Indonesian data were run together (intrinsic motivation of 0.84 , career motivation of 0.87 , grade motivation of 0.85 , self-determination of 0.82 , self-efficacy of 0.88 , and overall motivation of 0.94 ). According to a further interpretation of the person-reliability coefficient that is based on the research of Linacre (2012), a value of more than 0.8 provides a test that can effectively differentiate the sample into two or three levels based on the item difficulty. In addition, in terms of the item reliability, which is defined as the effectiveness of the item sample sizes that are in an accurate location on the latent variable (Linacre, 2012), all of the obtained coefficients are more than 0.95 (intrinsic motivation of 0.98 , career motivation of 0.99 , grade motivation of 0.98 , self-determination of 1.00 , self-efficacy of 0.95 , and overall motivation of 0.99 ).

Besides the reliability analysis for which the IRT-Rasch model was used, the reliabilities for which the CTT method was used, known as the Cronbach's alpha (internal consistency of the item), also provided values of more than 0.8 (intrinsic motivation of 0.87 , career motivation of 0.91 , grade motivation of 0.91 , self-determination of 0.84 , self-efficacy of 0.91 , and overall motivation of 0.96). According to Fisher (2008), the person and item reliabilities that are obtained from the Rasch analysis can also be interpreted using the alpha benchmark, and based on DeVellis (2003), an alpha that is more than 0.8 indicates a reliable instrument. 
Table 2. Validity and reliability results of the SMQ II

\begin{tabular}{|c|c|c|c|c|c|c|}
\hline \multirow{2}{*}{ Components } & & \multicolumn{2}{|c|}{ Item-fits } & \multirow{2}{*}{ - Person Reliability } & \multirow{2}{*}{ Item Reliability } & \multirow{2}{*}{ Cronbach's alpha } \\
\hline & & Infit MNSQ & Outfit MNSQ & & & \\
\hline \multirow{2}{*}{ Overall Motivation } & Lowest & 0.66 & 0.68 & \multirow{2}{*}{0.94} & \multirow{2}{*}{0.99} & \multirow{2}{*}{0.96} \\
\hline & Highest & 1.45 & 1.48 & & & \\
\hline \multirow{2}{*}{ Intrinsic Motivation } & Lowest & 0.78 & 0.77 & \multirow{2}{*}{0.84} & \multirow{2}{*}{0.98} & \multirow{2}{*}{0.87} \\
\hline & Highest & 1.25 & 1.25 & & & \\
\hline \multirow{2}{*}{ Career Motivation } & Lowest & 0.66 & 0.66 & \multirow{2}{*}{0.87} & \multirow{2}{*}{0.99} & \multirow{2}{*}{0.91} \\
\hline & Highest & 1.24 & 1.23 & & & \\
\hline \multirow{2}{*}{ Grade Motivation } & Lowest & 0.73 & 0.71 & \multirow{2}{*}{0.85} & \multirow{2}{*}{0.98} & \multirow{2}{*}{0.91} \\
\hline & Highest & 1.24 & 1.19 & & & \\
\hline \multirow{2}{*}{ Self-determination } & Lowest & 0.91 & 0.89 & \multirow{2}{*}{0.82} & \multirow{2}{*}{1.00} & \multirow{2}{*}{0.84} \\
\hline & Highest & 1.13 & 1.13 & & & \\
\hline \multirow{2}{*}{ Self-efficacy } & Lowest & 0.84 & 0.82 & \multirow{2}{*}{0.88} & \multirow{2}{*}{0.95} & \multirow{2}{*}{0.91} \\
\hline & Highest & 1.14 & 1.11 & & & \\
\hline
\end{tabular}

\section{Differential item functioning (DIF)}

The differential item functioning (DIF) is another analysis that can be performed with the utilization of the IRTRasch model. Also called the item-bias analysis, it is defined as the analysis for the investigation of whether one sample group could easily agree with an item compared with other groups in the same population. The DIF was run to uncover whether the item bias occurred on the SMQ-II items for the Indonesian and Korean data. The data were divided into eight groups based on country, educational level, and gender (e.g., Indonesian-female middle school, Korean-male high school, etc.) for the running of the DIF analysis. The DIF benchmark that was suggested by Boone et al. (2014), who suggested that a DIF measurement of more than 0.64 and less than -0.64 indicated the occurrence of an item bias with a meaningful effect size, was followed for this study. The low percentage of the outage DIF measurement for which the data of this study were used indicates a low bias item.

\section{Data Analyses}

The previously mentioned dimensionality issue was addressed using the ACER ConQuest version 4.5.0 (ACER, Australia), while the investigation of the item fits and the DIF data were conducted using WINSTEP version 3.92.1. Once the IRT-Rasch analysis was performed, a set of interval-scale values, the person ability that refers to every student's abilities according to the instrumental assessment, can be obtained. The five-dimensional Rasch model was applied to the authors' SMQ-II data so that every student has five person-ability values, each of which is for each of the constructs. These person-ability values were used for a further statistical analysis.

The three-way analyses of variance (ANOVA) were performed to examine the interaction effects of country, educational level, and gender on the student science learning motivation. The three-way ANOVA was run five times, as follows: once for each type of motivation. Following the analysis that was performed to address the research-question answer regarding the different educational levels and genders of the Korean and Indonesian students in terms of the correlations between one type of motivation and the other types, the Pearson-correlation tests were performed. All of the statistical analyses as well as the Cronbach's-alpha test were run using the SPSS version 22.

\section{FINDINGS}

\section{Comparison of the Science Motivation between the Indonesian and Korean Secondary Students}

Career motivation. The mean differences between the science career motivation based country, gender, and education years are visualized in Figure 1. Based on the results that were computed using the three-way ANOVA analysis, significant country $\left(F[1,1808]=59.38, p<0.01, \eta_{p}^{2}=0.032\right)$ and grade $\left(F[1,1808]=11.79, p<0.01, \eta_{p}^{2}=\right.$ $0.006)$ effects were found regarding the student science-career motivation. In contrast, a significant gender effect $\left(\mathrm{F}[1,1808]=1.02, \mathrm{p}>0.05, \eta_{\mathrm{p}}^{2}=0.001\right)$ regarding the student science-career motivation was not found. When the analyses were combined, a significant interaction was found between country and educational level $(\mathrm{F}[1,1808]=$ $\left.19.78, \mathrm{p}<0.01, \mathrm{\eta}_{\mathrm{p}}{ }^{2}=0.011\right)$; but in contrast, significant interactions between country and gender $(\mathrm{F}[1,1808]=0.83$, $\left.\mathrm{p}>0.05, \eta_{\mathrm{p}}{ }^{2}=0.000\right)$ and between gender and educational level $\left(\mathrm{F}[1,1808]=0.39, \mathrm{p}>0.05, \eta_{\mathrm{p}}^{2}=0.000\right)$ were not 

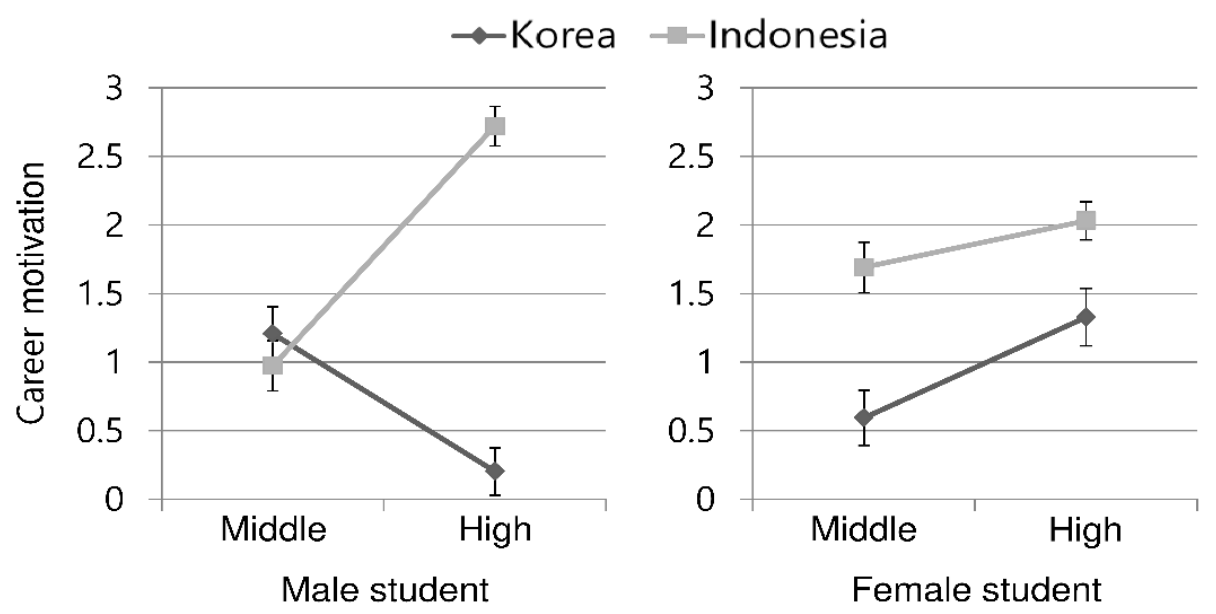

Figure 1. Comparison between Indonesian and Korean students for gender and educational level regarding the career motivation
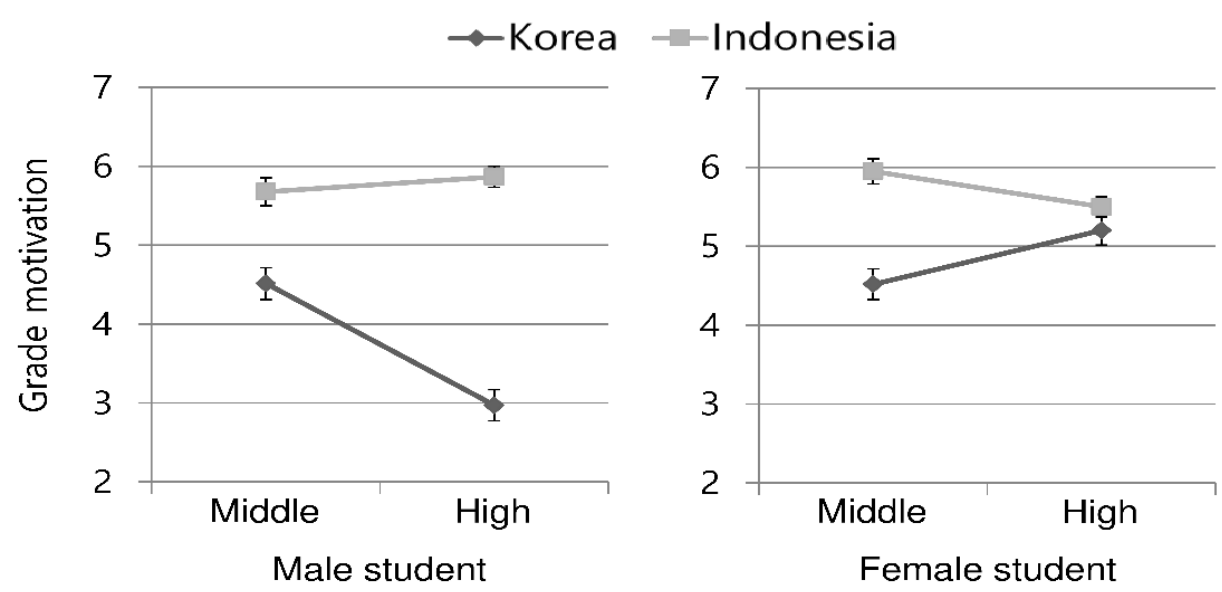

Figure 2. Comparison between Indonesian and Korean students for gender and educational level regarding the science-grade motivation

found. Lastly, a significant effect of the three-way interaction $\left(F[1,1808]=35.22, p<0.01, \eta_{p}{ }^{2}=0.019\right)$ between country, gender, and educational level was found.

A significant interaction effect among the three group variables means that the differences between the students' career-motivation levels are affected by the combination of country, gender, and educational level rather than a single group variable. As shown in Figure 1, in the case of the Korean male students, the high-school students showed much lower levels of the career motivation than the middle-school students. Alternatively, the career motivation of the Indonesian male high-school students is higher than that of the Indonesian male middle-school students. The female high-school students of both countries also showed a higher career motivation than the female middle-school students.

Grade motivation. The mean differences between the grade-motivation-based country, gender, and education years are visualized in the Figure 2. Based on the results that were computed using the three-way ANOVA analysis, significant effects of country $\left(F[1,1808]=123.27, p<0.01, \eta_{p}^{2}=0.064\right)$, gender $\left(F[1,1808]=16.83, p<0.01, \eta_{p^{2}}=\right.$ $0.009)$, and grade $\left(F[1,1808]=4.65, p<0.05, \eta_{p}^{2}=0.003\right)$ are evident on the student science grade motivation. Significant findings were also obtained from the effects of the interaction between country and gender $(F[1,1808]$ $\left.=19.93, p<0.01, \eta_{p}{ }^{2}=0.011\right)$ and the interaction between gender and grade $\left(F[1,1808]=9.28, p<0.01, \eta_{p}{ }^{2}=0.005\right)$. In contrast, a significant effect from the interaction between country and grade $\left(F[1,1808]=1.32, p>0.05, \eta_{p}^{2}=\right.$ $0.001)$ was not found. Ultimately, a significant effect of the three-way interaction $\left(F[1,1808]=30.29, p<0.01, \eta_{p}^{2}=\right.$ 0.016 ) between country, gender, and educational level was found.

This result means that the differences between the students' grade-motivation levels are affected by the combination of country, gender, and educational level rather than one group variable. As shown in Figure 2, the 

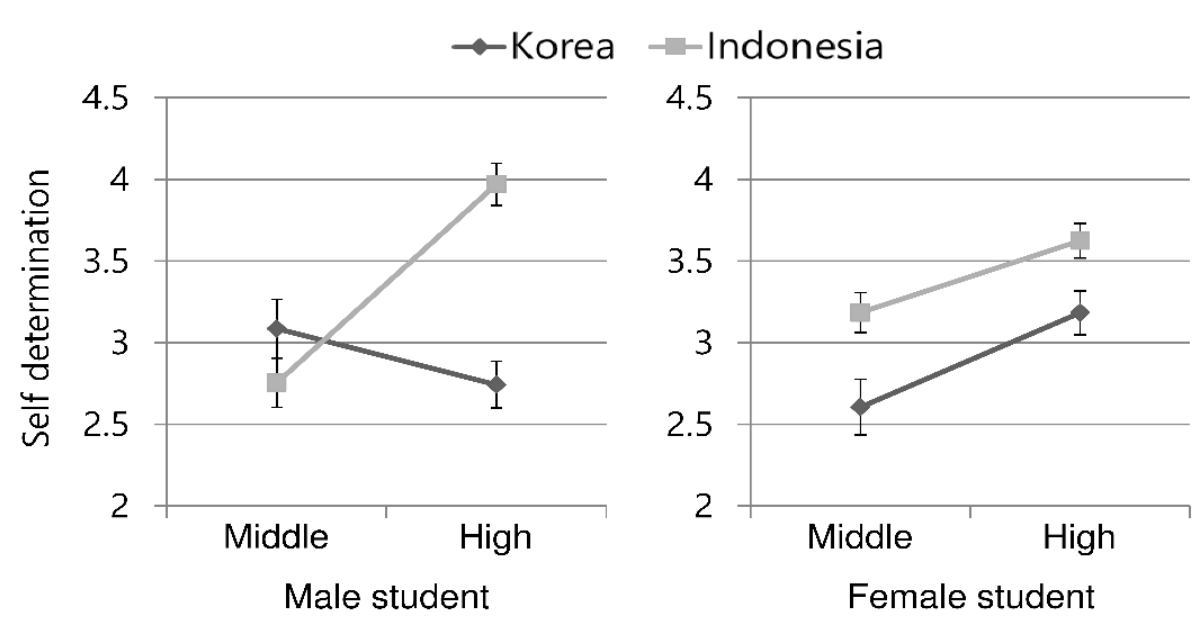

Figure 3. Comparison between Indonesian and Korean students for gender and educational level regarding self-determination

overall grade motivation of the Indonesian students is higher than that of the Korean students. Further, the grade motivation of the Korean male high-school students is much lower than that of the middle-school students. Meanwhile, the grade motivation of the Korean female high-school students is higher than that of the middleschool students.

Self-determination. The mean differences between the self-determination-based country, gender, and education years are visualized in Figure 3. According to the results that were obtained from the three-way ANOVA analysis, significant effects of country $\left(F[1,1808]=20.87, \mathrm{p}<0.01, \eta_{\mathrm{p}}^{2}=0.011\right)$ and grade $\left(F[1,1808]=20.30, \mathrm{p}<0.01, \eta_{\mathrm{p}}^{2}=\right.$ 0.011 ) were found regarding the science learning self-determination, but a significant gender effect is not evident on the secondary-student self-determination $\left(F[1,1808]=0.01, p>0.05, \eta_{p}{ }^{2}=0.000\right)$. As well as the absence of a significant gender-based finding, significant effects of the interaction between country and gender $(F[1,1808]=$ $\left.0.09, \mathrm{p}>0.05, \eta_{\mathrm{p}}{ }^{2}=0.000\right)$ and between gender and educational level $\left(\mathrm{F}[1,1808]=0.12, \mathrm{p}>0.05, \eta_{\mathrm{p}}{ }^{2}=0.000\right)$ are not evident; however, a significant effect of the interaction between country and educational level $(F[1,1808]=11.49, p$ $\left.<0.01, \eta_{\mathrm{p}}{ }^{2}=0.006\right)$ was found. Lastly, a significant effect of the three-way interaction $(\mathrm{F}[1,1808]=16.35, \mathrm{p}<0.01$, $\left.\eta_{\mathrm{p}}{ }^{2}=0.009\right)$ between country, gender, and educational level is evident.

This result means that the differences between the self-determination levels of the students are affected by the combination of country, gender, and educational level rather than one group variable. The overall differences between the self-determination levels according to the combination of the group variables show a pattern that is similar to that of the career motivation. As shown in Figure 3, in the case of the Korean male students, the highschool students showed a lower level of self-determination than the middle-school students. Alternatively, the selfdetermination of the Indonesian male high-school students is much higher than that of the Indonesian male middleschool students. The female high-school students of both countries also showed higher self-determination levels than the female middle-school students.

Self-efficacy. The mean differences between the self-efficacy-based country, gender, and education years are visualized in Figure 4. Based on the results that were computed using the three-way ANOVA analysis, a significant country effect $\left(F[1,1808]=154.01, p<0.01, \eta_{p}{ }^{2}=0.078\right)$ was found for self-efficacy, but in contrast, a significant effect $\left(F[1,1808]=2.13, p>0.05, \eta_{p}{ }^{2}=0.001\right)$ is not evident for the gender and the grade in terms of the self-efficacy $\left(F[1,1808]=1.36, p>0.05, \eta_{p}{ }^{2}=0.001\right)$. Similarly, significant-effect findings were not obtained from the interactions between country and gender $\left(F[1,1808]=0.47, p>0.05, \eta_{p}{ }^{2}=0.000\right)$ and between country and educational level $\left(F[1,1808]=0.09, p>0.05, \eta_{p}^{2}=0.000\right)$. By contrast, a significant effect of the interaction between gender and grade $\left(F[1,1808]=4.93, p<0.05, \eta_{p}^{2}=0.003\right)$ was found. Lastly, a significant effect of the three-way interaction between country, gender, and educational level $\left(F[1,1808]=15.13, p<0.01, \eta_{p}{ }^{2}=0.008\right)$ was found. 

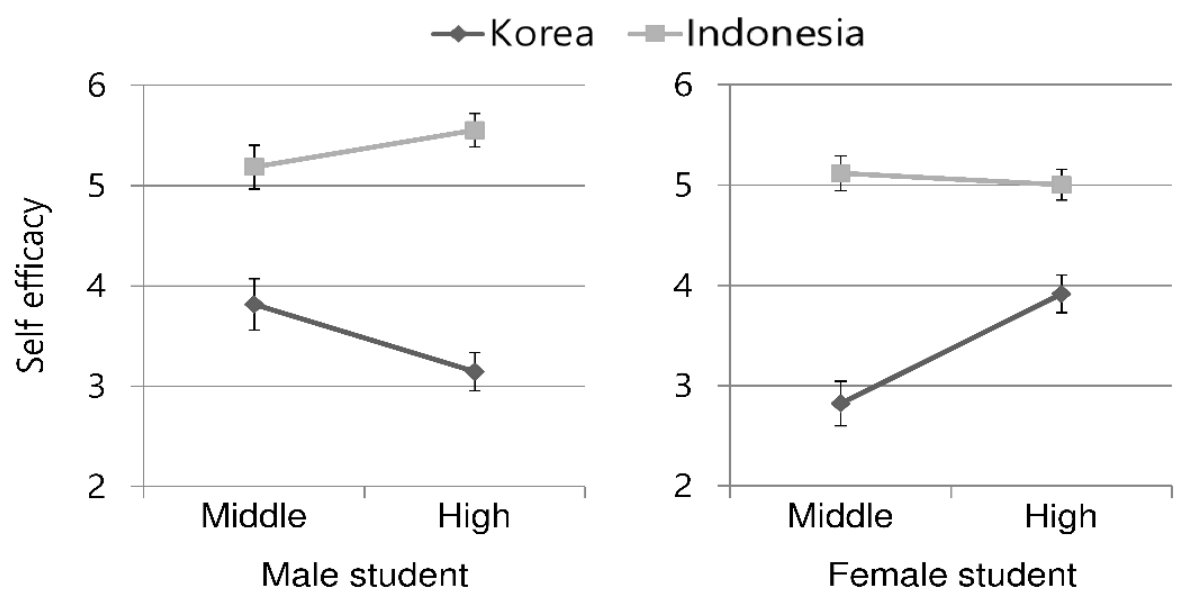

Figure 4. Comparison between Indonesian and Korean students for gender and educational level regarding self-efficacy
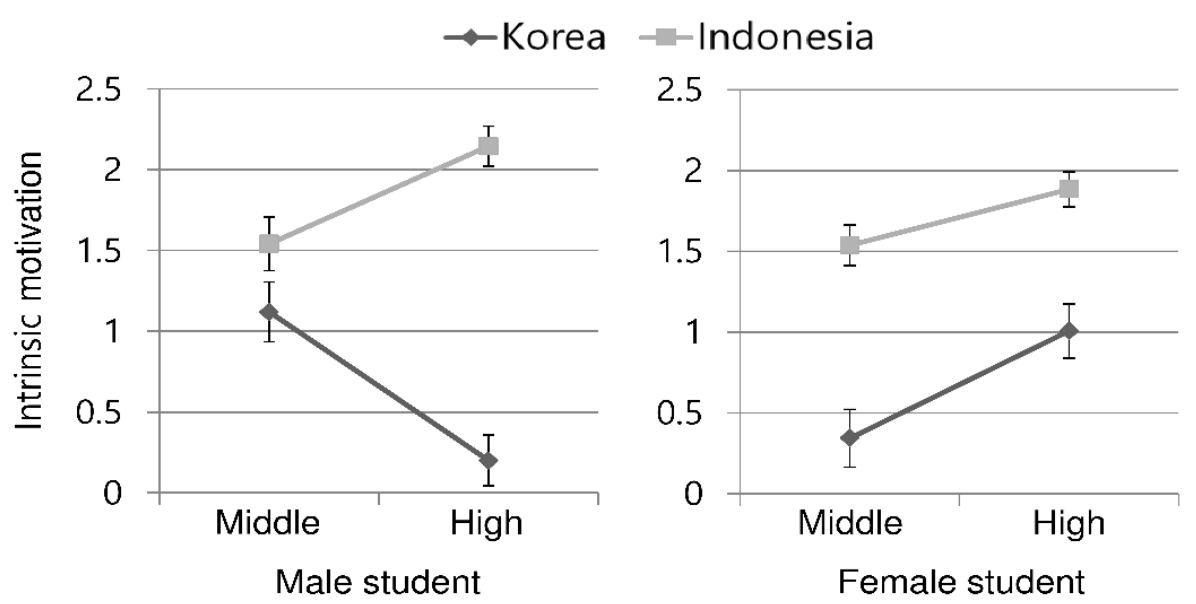

Figure 5. Comparison between Indonesian and Korean students for gender and educational level regarding intrinsic motivation

This result means that the differences of the self-efficacy levels of the students are affected by the combination of country, gender, and educational level rather than one group variable. As shown in Figure 4, the overall selfefficacy of the Indonesian students is higher than that of the Korean students, and only slight differences in the selfefficacy levels according to gender and educational level are evident. The self-efficacy of the Korean male highschool students is lower than that of the middle-school students, and the self-efficacy of the Korean female highschool students is higher than that of the middle-school students.

Intrinsic motivation. The mean differences between the intrinsic-motivation-based country, gender, and education years are visualized in Figure 5. Based on the results that were obtained from the three-way ANOVA analysis, a significant effect of country $\left(F[1,1808]=97.49, p<0.01, \eta_{p}{ }^{2}=0.051\right)$ was found; but in contrast, significant effects of gender $\left(F[1,1808]=0.28, p>0.05, \eta_{p}{ }^{2}=0.000\right)$ and educational level $\left(F[1,1808]=2.38, p>0.05, \eta_{p}{ }^{2}=0.001\right)$ are not evident when they are separately examined. A significant-finding effect is also absent in the interaction between country and gender $\left(F[1,1808]=0.44, p>0.05, \eta_{p}{ }^{2}=0.000\right)$, whereas significant effects occurred in the interactions between country and educational level $\left(F[1,1808]=7.19, p<0.01, \eta_{p^{2}}=0.004\right)$ and between country and gender $\left(F[1,1808]=8.70, p<0.01, \eta_{p}^{2}=0.005\right)$. Lastly, a significant effect of the three-way interaction between country, gender, and educational level $\left(F[1,1808]=16.75, p<0.01, \eta^{2}=0.009\right)$ is evident.

This result means that the differences of the students' intrinsic-motivation levels are affected by the combination of country, gender, and educational level rather than one group variable. As shown in Figure 5, the pattern of the difference of the overall intrinsic motivation according to the combination of the group variables is similar to those of the career motivation and the self-determination. The Indonesian students showed a relatively higher intrinsic motivation than the Korean students, and in the case of the Korean male students, the high-school students showed a much lower intrinsic motivation than the middle-school students. Alternatively, the self-determination of the Indonesian male high-school students is much higher than that of the Indonesian male middle-school students. The 
Table 3. The summary of the results of three-way ANOVA

\begin{tabular}{|c|c|c|}
\hline Motivation components & Interaction effects * & Effect size $\left(\eta_{p}{ }^{2}\right)$ \\
\hline Career motivation & Significant** & 0.019 \\
\hline Grade motivation & Significant** & 0.016 \\
\hline Self-efficacy & Significant** & 0.009 \\
\hline Self-determination & Significant** & 0.008 \\
\hline Intrinsic motivation & Significant** & 0.009 \\
\hline
\end{tabular}

Table 4. Pearson correlation coefficients (all correlations are significant at 0.01)

\begin{tabular}{|c|c|c|c|c|c|c|c|c|c|}
\hline & & \multicolumn{4}{|c|}{ Korea } & \multicolumn{4}{|c|}{ Indonesia } \\
\hline & & \multicolumn{2}{|c|}{ Middle } & \multicolumn{2}{|c|}{ High } & \multicolumn{2}{|c|}{ Middle } & \multicolumn{2}{|c|}{ High } \\
\hline \multicolumn{2}{|l|}{ Variables } & Male & Female & Male & Female & Male & Female & Male & Female \\
\hline \multirow{4}{*}{ Career motivation } & Grade motivation & 0.456 & 0.225 & 0.462 & 0.423 & 0.154 & 0.243 & 0.249 & 0.244 \\
\hline & Self-determination & 0.524 & 0.514 & 0.407 & 0.329 & 0.144 & 0.256 & 0.186 & 0.127 \\
\hline & Self-efficacy & 0.520 & 0.448 & 0.507 & 0.434 & 0.179 & 0.178 & 0.129 & 0.107 \\
\hline & Intrinsic motivation & 0.618 & 0.621 & 0.610 & 0.634 & 0.300 & 0.279 & 0.125 & 0.132 \\
\hline \multirow{3}{*}{ Grade motivation } & Self-determination & 0.587 & 0.241 & 0.460 & 0.402 & 0.259 & 0.245 & 0.342 & 0.275 \\
\hline & Self-efficacy & 0.572 & 0.299 & 0.573 & 0.436 & 0.171 & 0.278 & 0.173 & 0.215 \\
\hline & Intrinsic motivation & 0.462 & 0.208 & 0.504 & 0.295 & 0.158 & 0.190 & 0.223 & 0.129 \\
\hline \multirow{2}{*}{ Self-determination } & Self-efficacy & 0.799 & 0.666 & 0.676 & 0.658 & 0.251 & 0.361 & 0.165 & 0.275 \\
\hline & Intrinsic motivation & 0.702 & 0.645 & 0.529 & 0.442 & 0.341 & 0.346 & 0.258 & 0.220 \\
\hline Self-efficacy & Intrinsic motivation & 0.682 & 0.624 & 0.605 & 0.540 & 0.340 & 0.276 & 0.267 & 0.240 \\
\hline
\end{tabular}

self-determination levels of the female high-school students of both countries are also higher than those of the female middle-school students.

Table 3 provides a summary of the statistical findings of the interactions between country, educational level, and gender throughout all of the components of the science learning motivation.

\section{Correlational Differences among the Science Motivational Components of the Indonesian and Korean Students}

As shown in Table 4, all of the motivational components are significantly correlated $(p<0.01)$ with one another in both the Indonesian and Korean samples for which the gender and the educational level were varied. In the comparison of the correlation coefficients among the male samples, both the Indonesian middle- and high-school students showed a weaker association between one component and another compared with the Korean middleand high-school students. For the Indonesian middle-school students, the lowest coefficient was the correlation between the career motivation and the self-determination $(r=0.144)$, whereas the highest correlation was between the self-determination and the intrinsic motivation $(r=0.341)$. For the Indonesian high-school students, the lowest coefficient was the correlation between the career motivation and the intrinsic motivation $(r=0.125)$, whereas the highest correlation was between the grade motivation and the self-determination $(r=0.342)$. In terms of the Korean middle- and high-school students, the lowest and highest correlations were those between the career motivation and the grade motivation $(r=0.456)$ and between the self-determination and the self-efficacy $(r=0.799)$, and those between the career motivation and the self-determination $(r=0.407)$ and between the self-determination and the self-efficacy $(r=0.676)$, respectively.

Similar findings were also found in the female-sample pools, where the educational levels of the Indonesian students were lower than those of the Korean students. Among the Indonesian middle- and high-school students, the lowest and highest associations were the correlations between the career motivation and the self-efficacy $(r=$ $0.178)$ and between the self-determination and the self-efficacy $(r=0.361)$, and those between the career motivation and the self-efficacy $(r=0.107)$ and between the grade motivation and the self-determination $(r=0.275)$, respectively. For the Korean middle- and high-school students, the lowest and highest associations were the correlations between the career motivation and the grade motivation $(r=0.225)$ and between the self-determination and the self-efficacy $(r=0.666)$, and those between the grade motivation and the intrinsic motivation $(r=0.295)$ and between the self-determination and the self-efficacy $(r=0.658)$, respectively. Overall, the Indonesian-student correlation coefficients are much lower than those of the Korean students. 


\section{DISCUSSIONS}

The current study demonstrates the interactions between the three most significant contributing factors regarding the student science learning motivation, as follows: country, gender, and educational level. The effects of these three factors on the associations among the science motivation components were also examined. This section will discuss the findings in two parts, one for each research question.

\section{Effect of the Interactions between Country, Gender, and Educational Level on the Student Science Motivation}

In response to the first research question that is addressed in this paper, the combination of country, gender, and educational level significantly define the student science learning motivation. Looking out in a more detail to the results of the five science motivational components, the current research has found two distinct patterns on the Indonesian samples, while the Korean samples showed the same pattern in all of the motivational components. As seen in visualizations of the results for all motivational components (Figure 1 to $\mathbf{5}$ ), the Korean samples showed that male students tended to have declining trends from middle school to high school students while female student's motivational components were prone to be increasing from middle to high school. The two patterns showed in the Indonesian samples were only exhibited as well in the female samples. The male samples had increasing trends in all motivational components, while the female students had only increasing trends in the career motivation, self-determination and intrinsic motivation. Interestingly, the results from the two other factors showed a stable-slightly-decreasing pattern from middle to high school level; these patterns are contrary to the results from Korean female students. In the overall assessments, the Indonesian male and female students slightly showed a quite non-extreme difference in all motivational components, while the identified Korean male and female students showed very different trends.

These findings could address what Bybee (2012) found in the PISA 2006 regarding the inconsistency of the student science learning motivation that varied between countries and also according to gender in particular countries. In addition, these findings can also be used as a response to the paper of Osborne et al. (2003), wherein it is stated that the attitudes in science including the science learning motivation are nebulous and are often not well understood. With the findings that have been obtained in this paper, we believe that the science learning motivation is indeed nebulous, and the findings are also inconsistent because the sole focus of most of the previous studies that investigated the student science learning motivation is merely the separate investigation of those three variables; that is, just country or culture or gender, or even just a specific level of education (e.g., Vedder-Weiss \& Fortus, 2012; Zeyer, 2018; Zeyer et al., 2013). Even international studies like the PISA and the TIMSS have not discussed or examined the interactions between all the three factors, as they have just used two of the three variables, country and gender.

Based on the findings, it is assumed that the interactions between the three factors occur as a part of a student motivational system. The authors believe that the societies of the world's countries, each with a unique and specific culture, treat every gender type differently. A type of treatment is the stereotypical perception of a particular society that science is a more masculine subject (Meece et al., 2006) such as in Korea (Narayan et al., 2013; OECD, 2016; Song \& Kim, 1999) and this result in the application of a strong pressure on male students to enroll in science subjects and pursue science-related careers. In fact, economically it is noted that Korea as a developed country comprises of many people working in the science-related fields leading to the low rate of job vacancy in the fields, also the increased difficulty level of science contents from middle to high schools taught with advanced science teaching and learning activities (such as the Research and Education or R\&E program), may contribute to the decreasing trends of Korean male students with a science learning motivation, as found in the results of current research. As the job issues may be the cause of the decreasing trend of Korean male student's career motivation, perhaps it also impacts their grade motivation as they are likely to not have the intention of obtaining a higher grade in a science subject. Moreover, R\&E programs infused in Korean science education is a program providing high school students to be engaged in more advanced science learning activities, such as experimenting, taken place in the nearest university labs and advised by the university's professor. Perhaps, this kind of program is taken in a more serious way leading to a loss of 'fun' activities in learning science that could decrease the student's science interest, in which an important aspect for a student to be more intrinsically motivated, self-determined and having more confidence or self-efficacy in learning science. As Jack and Lin (2017) argue that intriguing science classes are the most crucial concepts necessary to appeal to students to have more interest in science leading to producing more intrinsically motivated students.

It is noted that in comparison to the Korean male students, its female students had shown increasing trends in all motivational components. Along with the higher educational levels they were showed to be more extrinsically and intrinsically motivated, self-determined and confident individuals. We are assuming what made Korean female students were found different to the male students is perhaps that they are not much impacted by the 'masculinity' 
perspective of science, so that they do not have much pressure and anxiety in learning science, and they may feel more comfortable to learning it without any demand of excelling in this particular subject from their parents, teachers and/or society. This may lead to make them a more intrinsically motivated individual. As Zeyer (2018) assumes that once students are becoming more intrinsically motivated individuals, they tend to have more interest and curiosity in higher or advanced level of science contents, thinking and/or learning activities, including the R\&E program. Moreover, as the response to the UNESCO's report (UNESCO, 2015) regarding Korea as one of the lowest equity of gender-based statistics as associated in science-related careers, which are still dominated by males, the Korean government now is attempting to reduce this low gender equity labelling by increasing the number of women working in the science-related fields through the various policies and campaigns for women in fields of science and technology such as 'Women Into Science \& Engineering (WISE)' from 2002 (Lee, 2012). The campaign may potentially contribute to the attracting of Korean female students to pursuing jobs in science-related fields, and as found in a current study of Korean female students that this effort had an increasing trend in the science careers and the student's grade motivation.

In terms of the findings from the Indonesian male students, the Indonesian male students were found on the opposite trends with the Korean male students for all motivational components. It is noted that the Indonesian male students had increasing trends in the five motivational components, along with the higher level of education. Perhaps this is caused by the label of developing country that Indonesia has had to date. Indonesia now is trying to put much effort into increasing the number of individuals working in the science-related fields, thus it provides more job vacancies with higher salaries that appeals to both Indonesian male and female students, when it is time for them to go out pursuing their jobs after graduation. Moreover, more than two centuries of Indonesian people have brought gender equality as an important concept in various aspects of life (Martyn, 2005), and it has resulted with the negligible gap or quite an equal number of both genders working in science-related jobs (UNESCO, 2015). This gender equality movement is likely to decrease the impact of the masculinity assumption that science subjects are perceived. However, gender bias may also still exist, as a current research found female students tended to have a decreasing trend in grade motivation and self-efficacy along with their educational levels. The science contents in Indonesian science curriculum may be considered as one of the causes. In Indonesia, the high school science contents tend to be more cognitive challenging than those in middle school level, and as Zeyer (2018) stated that male students are prone to be more attracted to the cognitive challenging concepts which are leading to be more active in science class and better at gaining the attention from the teachers, which allows them to earn a higher grade. As male students are more skilled at gaining more attention from the instructor in the classroom, it may impact female students to realize that they may not be able to obtain higher grade in more challenging science class and will thereby serve to decrease their self-efficacy or confidence to become a success in the challenging nature of a science class. However, it should be emphasized that the differences were quite low.

Taken altogether and reviewing the interpretations, what has caused Indonesian male-female students in the high school level to be superior in their five science learning motivational-based components than the Korean malefemale students? We believe the impact of the 'fun' rate and the society pressure are the causing this significant differences among the students. As previously mentioned, it is noted that Korean science classes are mainly more challenging and more advanced, like an R\&E program which has less 'fun' on the application, together with 'Education Fever' in the Korean society and pressure to get a high score in the college entrance exam for gaining an advantage for enrollment to prestigious universities have impacted their motivation to learn science and could not exceed the Indonesian student's motivation to learn science. In Indonesia, science is still taught traditionally, where observations of the surrounding environment and the Indonesian biodiversity context are used, and therefore, more learning activities occur outside the classroom and this is of greater interest to the students. Also, Indonesian parents, teachers and society are not heavily putting pressure onto students to get into the highest quality ranked universities. This has resulted in the phenomenon of a noted higher science motivation that Indonesian students had as compared to the motivation noted with the Korean students. Furthermore, as most Indonesian science classrooms are currently still likely using traditional methods of teaching, even though it could elevate the impetus of the student's science learning motivation, it is noted that the effort fails to increase scientific literacy for those students in that case. The Korean situation as noted in the classroom is likely to be considered the opposite scenario, and it could be noted to increase the student's associated scientific literacy, but not their science motivation.

Based on the idea of making sense of the current research's findings, we believe that refinement in the society and science curriculum may be taken as the important effort to manage the concept that will work towards aligning scientific literacy level and motivation for the students to want to learn about science in the classroom. The results from these two countries, Indonesia and Korea, suggest that putting less pressure to both genders by not labelling science subjects as a traditional masculine subject, giving attention equally, having a more 'fun' science class, but still not losing the basic scientific literacy competencies, may be considered as the effort that may work to achieve the goal to have a higher motivation to learn science. By taking into account the interactions of the three factors, this study found the patterns of motivation that are distinguished by the combination of these factors. These distinctive patterns mean that some science teaching-learning strategies that are suggested globally as seen and 
noted as an effective way to improve science learning motivation, but these strategies cannot work for each student identically in the classroom, and for that reason the science educator needs to consider the student's motivational characteristics with noting the complexity of the class being taught. However, we also want to emphasize here that we discuss the interactions between the three factors as correlational, and one concept which is one factor impacting another factor and also impacting another, given that it is quite difficult to discuss all factors together by using only our obtained statistical data. Thus, we are aware of this issue as part of the limitation of the current research.

\section{Differences of the Science Learning Motivation Structure between Indonesian and Korean Secondary Students}

A correlation test was used to formulate a response that addresses the second research question regarding the structural differences between the Indonesian and Korean secondary-student science learning motivations, and for the identification of these differences as one of the direct effects of the interactions between the three previously mentioned variables. The direct effect of the interactions between those three variables on the student science learning motivation was suggested by the findings of the Pearson-correlation tests that are presented in Table 4 . Even though, based on the findings of Table 4, the motivational levels of both the male and female Indonesian students in middle school and high school are higher than those of the Korean students, the correlation between one of the motivational components and the others were much weaker than that of the Korean students. It is suggested that when the Indonesian students show a high value in one motivational component, the values of the other components are not high. In contrast, if the value of one of the motivational components is high for the Korean students, they might also show high scores in the other components. These findings could also be considered as a result of the motivational complexity.

The present findings suggest that a high science learning motivation does not exactly define the structural stability of every component so that they are highly correlated with one another. The weak correlation that is exhibited in the Indonesian sample suggests that the motivation to learn science cannot be assumed as one latent variable, and that a different sample type can produce more than one latent motivational variable. The complexity of the science learning motivation, as well as the treatment of the dimensionality of the motivational instrument, is crucial for the attainment of a more meaningful outcome and to uncover the vagueness of the student science learning motivation.

\section{CONCLUSIONS}

In brief, unlike the previous study that simply compared the science learning motivation in terms of particular variables, such as the sole consideration of gender, the significance of this study is the unveiling of the complexity of the interactions between the following three factors that provide the greatest contributions regarding the student science learning motivation: country, gender, and educational level. With the use of statistical evidence, the current work has found that the process for the defining of the student science learning motivation is more complex than that of the previous conception. The interactions between the different kinds of culture in particular countries that treat every gender differently, and the impact on the curriculum and the teaching practices at the different educational levels, means that the defining of the student science learning motivation is not a straightforward matter.

\section{REFERENCES}

Adams, R., \& Wu, M. (2010). Notes and tutorial Conquest: Multidimensional model. Retrieved from https://www.acer.org/conquest/notes-tutorials

Alexander, J. M., Johnson, K. E., \& Kelley, K. (2012). Longitudinal analysis of the relations between opportunities to learn about science and the development of interests related to science. Science Education, 96(5), 763-786. https:/ / doi.org/10.1002/sce.21018

Bandura, A. (1986). Social foundations of thought and action: A social cognitive theory. Englewood Cliffs, NJ: Prentice Hall.

Bandura, A. (1997). Self-efficacy: The Exercise of Control. New York, NY: Freeman.

Boone, W. J., Staver, J. R., \& Yale, M. S. (2014). Rasch analysis in the human sciences. Dordrecht: Springer. https:/ / doi.org/10.1007/978-94-007-6857-4

BPS [Badan Pusat Statistik/ Statistics Indonesia]. (2013). Penduduk Menurut Wilayah dan Agama yang Dianut. Retrieved March 10, 2017, from http://sp2010.bps.go.id/index.php/site/tabel?tid=321 
Britner, S. L. (2008). Motivation in high school science students: A comparison of gender differences in life, physical, and earth science classes. Journal of Research in Science Teaching, 45(8), 955-970. https:// doi.org/10.1002/tea.20249

Bybee, R.W. (2012). Scientific literacy in environmental and health education. In Zeyer, A., \& Kyburz-Graber, R. (pp. 49-67). Science Environment Health. Dordrecht: Springer. https://doi.org/10.1007/978-90-481-3949-1_4

Cavas, P. (2011). Factors Affecting the Motivation of Turkish Primary Students for Science Learning. Science Education International, 22(1), 31-42.

Chin, C., \& Brown, D. E. (2000). Learning in science: A comparison of deep and surface approaches. Journal of Research in Science Teaching, 37(2), 109-138. https: / / doi.org/10.1002/(SICI)1098-2736(200002)37:2<109::AIDTEA3>3.0.CO;2-7

Chiu, M. M., \& Xihua, Z. (2008). Family and motivation effects on mathematics achievement: Analyses of students in 41 countries. Learning and Instruction, 18(4), 321-336. https:/ / doi.org/10.1016/j.learninstruc.2007.06.003

Dalgety, J., \& Coll, R. K. (2006). Exploring first-year science students' chemistry self-efficacy. International Journal of Science and Mathematics Education, 4(1), 97-116. https:/ / doi.org/10.1007/s10763-005-1080-3

DeBacker, T. K., \& Nelson, R. M. (2000). Motivation to learn science: Differences related to gender, class type, and ability. The Journal of Educational Research, 93(4), 245-254. https:/ / doi.org/10.1080/00220670009598713

DeVellis, R. F. (2003). Scale development: Theory and applications ( $2^{\text {nd }}$ edn.). Thousand Oaks, CA: Sage.

Elliot, A. J., \& Moller, A. C. (2003). Performance-approach goals: Good or bad forms of regulation? International Journal of Educational Research, 39(4), 339-356. https:/ / doi.org/10.1016/j.ijer.2004.06.003

Fisher, W. P. (2008). The cash value of reliability. Rasch Measurement Transactions, 22(1), 1160-1163.

Fortus, D. (2014). Attending to affect. Journal of Research in Science Teaching, 51(7), 821-835. https://doi.org/10.1002/tea.21155

Galton, M. (2009). Moving to secondary school: Initial encounters and their effects. Perspectives on Education (Primary Secondary Transfer in Science), 2, 5-21.

Glynn, S. M., Brickman, P., Armstrong, N., \& Taasoobshirazi, G. (2011). Science Motivation Questionnaire II: Validation with science majors and non-science majors. Journal of Research in Science Teaching, 48(10), 11591176. https:// doi.org/10.1002/tea.20442

Glynn, S. M., Taasoobshirazi, G., \& Brickman, P. (2009). Science motivation questionnaire: Construct validation with nonscience majors. Journal of Research in Science Teaching, 46(2), 127-146. https:/ / doi.org/10.1002/tea.20267

Gottfried, A. E., Fleming, J. S., \& Gottfried, A. W. (2001). Continuity of academic intrinsic motivation from childhood through late adolescence: A longitudinal study. Journal of Educational Psychology, 93(1), 3-13. https://doi.org/10.1037/0022-0663.93.1.3

Graham, S., \& Taylor, A. Z. (2002). Ethnicity, gender, and the development of achievement values. In J. S. Eccles, \& A. Wigfield (Eds.), A volume in the educational psychology series. Academic Press. https:/ / doi.org/10.1016/B978-012750053-9/50007-3

Hofstede, G. (2003). Culture's consequences. Thousand Oaks, CA: Sage

Jack, B. M., \& Lin, H. S. (2017). Making learning interesting and its application to the science classroom. Studies in Science Education, 53(2), 137-164. https: / / doi.org/10.1080/03057267.2017.1305543

Jarvis, T., \& Pell, A. (2005). Factors influencing elementary school children's attitudes toward science before, during, and after a visit to the UK National Space Centre. Journal of Research in Science Teaching, 42(1), 53-83. https:/ / doi.org/10.1002/tea.20045

Jones, R. (2013). Education Reform in Korea. OECD Economics Department Working Papers, No. 1067. Paris: OECD Publishing. https://doi.org/10.1787/5k43nxs1t9vh-en

Jones, S. M., \& Dindia, K. (2004). A meta-analytic perspective on sex equity in the classroom. Review of Educational Research, 74(4), 443-471. https:/ / doi.org/10.3102/00346543074004443

Jussim, L., \& Harber, K. D. (2005). Teacher expectations and self-fulfilling prophecies: Knowns and unknowns, resolved and unresolved controversies. Personality and Social Psychology Review, 9(2), 131-155. https://doi.org/10.1207/s15327957pspr0902_3

Koballa, T. R., \& Glynn, S. M. (2007). Attitudinal and motivational constructs in science learning. In S. K. Abell \& N. G. Lederman (Eds), Handbook of Research on Science Education (pp. 75-102). New York, NY: Routledge.

Larson, R., Dworkin, J., \& Gillman, S. (2001). Facilitating adolescents' constructive use of time in one-parent families. Applied Developmental Science, 5(3), 143-157. https://doi.org/10.1207/S1532480XADS0503_3 
Lau, S., \& Roeser, R. W. (2002). Cognitive abilities and motivational processes in high school students' situational engagement and achievement in science. Educational Assessment, 8(2), 139-162. https:/ / doi.org/10.1207/S15326977EA0802_04

Lee, C. S., Hayes, K. N., Seitz, J., DiStefano, R., \& O'Connor, D. (2016). Understanding motivational structures that differentially predict engagement and achievement in middle school science. International Journal of Science Education, 38(2), 192-215. https: / / doi.org/10.1080/09500693.2015.1136452

Lee, E. (2012). From gender to human resource: The growth of Korean policy for women in science \& technology and its limit. Gender and Culture, 5(2), 7-35.

Lee, O., \& Brophy, J. (1996). Motivational patterns observed in sixth-grade science classrooms. Journal of Research in Science Teaching, 33(3), 303-318. https://doi.org/10.1002/(SICI)1098-2736(199603)33:3<303::AIDTEA4>3.0.CO;2-X

Leigh, A., \& Van der Eng, P. (2009). Inequality in Indonesia: What can we learn from top incomes? Journal of Public Economics, 93(1), 209-212. https:/ / doi.org/10.1016/j.jpubeco.2008.09.005

Lepper, M. R., Corpus, J. H., \& Iyengar, S. S. (2005). Intrinsic and extrinsic motivational orientations in the classroom: Age differences and academic correlates. Journal of Educational Psychology, 97(2), 184-196. https:/ / doi.org/10.1037/0022-0663.97.2.184

Libao, N. J. P., Sagun, J. J. B., Tamangan, E. A., Pattalitan, A. P., Dupa, M. E. D., \& Bautista, R. G. (2016). Science learning motivation as correlate of students' academic performances. Journal of Technology and Science Education, 6(3), 209-218. https:/ / doi.org/10.3926/jotse.231

Linacre, J. M. (2012). A user's guide to Winsteps Ministeps Rasch-model computer programs [version 3.74.0]. Retrieved from http://www.winsteps.com/winsteps.htm

Maltese, A. V., \& Tai, R. H. (2010). Eyeballs in the fridge: Sources of early interest in science. International Journal of Science Education, 32(5), 669-685. https:/ / doi.org/10.1080/09500690902792385

Martyn, E. (2005). The woman's movement in post-colonial Indonesia. New York, NY: Routledge Curzon. https:// doi.org/10.4324/9780203299197

Mason, L. Boscolo, P., Tornatora, M. C., \& Ronconi, L. (2012). Besides knowledge: A cross-sectional study on the relations between epistemic beliefs, achievement goals, self-beliefs, and achievement in science. Instructional Science, 41(1), 49-79. https:/ / doi.org/10.1007/s11251-012-9210-0

McHale, S. M., Shanahan, L., Updegraff, K. A., Crouter, A. C., \& Booth, A. (2004). Developmental and individual differences in girls' sex-typed activities in middle childhood and adolescence. Child Development, 75(5), 15751593. https:/ / doi.org/10.1111/j.1467-8624.2004.00758.x

Meece, J. L., \& Kurtz-Costes, B. (2001). Introduction: The schooling of ethnic minority children and youth. Educational Psychologist, 36(1), 1-7. https://doi.org/10.1207/S15326985EP3601_1

Meece, J. L., Anderman, E. M., \& Anderman, L. H. (2006). Classroom goal structure, student motivation, and academic achievement. Annual Review of Psychology, 57, 487-503. https://doi.org/10.1146/annurev.psych.56.091103.070258

Meece, J. L., Glienke, B. B., \& Burg, S. (2006). Gender and motivation. Journal of School Psychology, 44(5), 351-373. https:// doi.org/10.1016/j.jsp.2006.04.004

Ministry of Education. (2015). The 2015 Revised Science Curriculum (Report No. 2015-74). Sejong: Ministry of Education.

Mullis, I. V. S., Martin, M. O., Foy, P., \& Hooper, M. (2016). TIMSS 2015 international results in science. Chesnut Hill, MA: TIMSS \& PIRLS International Study Center, Lynch School of Education, Boston College.

Murayama, K., Pekrun, R., Lichtenfeld, S. \& vom Hofe, R. (2013). Predicting long-term growth in student'smathematics achievement: The unique contributions of motivation and cognitive strategies. Child Development, 84(4), 1475-1490. https:/ / doi.org/10.1111/cdev.12036

Narayan, R., Park, S., Peker, D., \& Suh, J. (2013). Students' images of scientists and doing science: An international comparison study. Eurasia Journal of Mathematics, Science \& Technology Education, 9(2), 115-129.

Nugent, G., Barker, B., Welch, G. Grandgenett, N., Wu, C., \& Nelson, C. (2015). A model of factors contributing to STEM learning and career orientation. International Journal of Science Education, 37(7), 1067-1088. https:/ / doi.org/10.1080/09500693.2015.1017863

OECD. (2016). PISA 2015 Results (Volume I): Excellence and Equity in Education, PISA. Paris: OECD Publishing.

OECD. (2017). Education at a Glance 2017: OECD Indicators. Paris: OECD Publishing. http:/ / dx.doi.org/10.1787/888933560149 
Osborne, J., Simon, S., \& Collins, S. (2003). Attitudes towards science: A review of the literature and its implications. International Journal of Science Education, 25(9), 1049-1079. https:/ / doi.org/10.1080/0950069032000032199

Palmer, D. (2005). A motivational view of constructivist-informed teaching. International Journal of Science Education, 27(15), 1853-1881. https:/ / doi.org/10.1080/09500690500339654

Parker, L. (2017). Religious environmental education? The new school curriculum in Indonesia. Environmental Education Research, 23(9), 1249-1272. https:/ / doi.org/10.1080/13504622.2016.1150425

Pintrich, P. R. (2003). A motivational science perspective on the role of student motivation in learning and teaching contexts. Journal of Educational Psychology, 95(4), 667-686. https:/ / doi.org/10.1037/0022-0663.95.4.667

Pulfre, C., Buchs, C., \& Butera, F. (2011). Why grades engender performance-avoidance goals: The mediating role of autonomous motivation. Journal of Educational Psychology, 103(3), 683-700. https://doi.org/10.1037/a0023911

Ryan, R. M., \& Deci, E. L. (2000). Self-determination theory and facilitation of intrinsic motivation, social development, and well-being. American Psychologist, 55(1), 68-78. https://doi.org/10.1037/0003066X.55.1.68

Schunk, D. H., \& Usher, E. L. (2012). Social cognitive theory and motivation. In R. M. Ryan (Eds.), The Oxford Handook of Human Motivation (pp. 13-27). NY: Oxford University Press. https:/ / doi.org/10.1093/oxfordhb/9780195399820.013.0002

Schunk, D. H., Pintrich, P. R., \& Meece, J. L. (2008). Motivation in education (3rd edition). Upper Saddle River, NJ: Pearson.

Seth, M. J. (2002). Education fever: society, politics, and the pursuit of schooling in South Korea. University of Hawaii Press, Honolulu.

Shin, S., Lee, J. K., \& Ha, M. (2017). Influence of career motivation on science learning in Korean high-school students. EURASIA Journal of Mathematics Science and Technology Education, 13(5), 1517-1538. https:/ / doi.org/10.12973/eurasia.2017.00683a

Song, J., \& Kim, K. S. (1999). How Korean students see scientists: the images of the scientist. International Journal of Science Education, 21(9), 957-977. https:/ / doi.org/10.1080/095006999290255

Tang, M., \& Neber, H. (2008). Motivation and self-regulated science learning in high-achieving students: differences related to nation, gender, and grade-level. High Ability Studies, 19(2), 103-116. https:/ / doi.org/10.1080/13598130802503959

UNESCO (2015). A Complex Formula: Girls and Women in Science, Technology, Engineering and Mathematics in Asia. Bangkok: UNESCO.

UNICEF. (2001). The state of the world's children 2001. Retrieved from http:/ / www.unicef.org/sowc01/

Urdan, T., \& Schoenfelder, E. (2006). Classroom effects on student motivation: Goal structures, social relationships, and competence beliefs. Journal of School Psychology, 44(5), 331-349. https:/ / doi.org/10.1016/j.jsp.2006.04.003

Vedder-Weiss, D., \& Fortus, D. (2011). Adolescents' declining motivation to learn science: Inevitable or not? Journal of Research in Science Teaching, 48(2), 199-216. https:/ / doi.org/10.1002/tea.20398

Vedder-Weiss, D., \& Fortus, D. (2012). Adolescents' declining motivation to learn science: A follow-up study. Journal of Research in Science Teaching, 49(9), 1057-1095. https:/ / doi.org/10.1002/tea.21049

Vedder-Weiss, D., \& Fortus, D. (2013). School, teacher, peers, and parents' goals emphases and adolescents' motivation to learn science in and out of school. Journal of Research in Science Teaching, 50(8), 952-988. https:/ / doi.org/10.1002/tea.21103

Wigfield, A., Cambria, J., \& Eccles, J. S. (2012). Motivation in education. In R. C. Ryan (Ed.), Oxford Handbook of Motivation (pp.463-478). New York: Oxford University Press. https://doi.org/10.1093/oxfordhb/9780195399820.013.0026

Wright, B. D., \& Linacre, J. M. (1994). Reasonable mean-square fit values. Rasch Measurement Transactions, 8(3), 370.

Zeyer, A. (2018). Gender, complexity, and science for all: Systemizing and its impact on motivation to learn science for different science subjects. Journal of Research in Science Teaching, 55(2), 147-171. https:/ / doi.org/10.1002/tea.21413

Zeyer, A., Çetin-Dindar, A., Md Zain, A. N., Juriševič, M., Devetak, I., \& Odermatt, F. (2013). Systemizing: A crosscultural constant for motivation to learn science. Journal of Research in Science Teaching, 50(9), 1047-1067. https:// doi.org/10.1002/tea.21101

\section{http://www.ejmste.com}

